\title{
Nilai Antioksidan dan SPF dari Kombinasi Minyak Biji Wijen (Sesamum indicum L.) dan Minyak Biji Bunga Matahari (Helianthus annuus L.)
}

\author{
An Antioxidant and a SPF of Combination of Sesame Seed Oil (Sesamum \\ indicum L.) and Sunflower Seed Oil (Helianthus annuus L.)
}

\author{
Yanthy Susanti1 ${ }^{*}$, Anny Victor Purba², Deni Rahmat ${ }^{2}$ \\ ${ }^{1}$ Akademi Farmasi IKIFA, Jakarta \\ 2 Magister Farmasi, Universitas Pancasila, Jakarta \\ Corresponding author: Yanthy Susanti: Email: susantiyanthy@gmail.com \\ Submitted: 06-12-2019 Revised: 17-12-2019 Accepted: 26-12-2019
}

\begin{abstract}
ABSTRAK
Minyak wijen dan minyak biji bunga matahari yang mengandung Vitamin E dan $\beta$-Karoten dilaporkan memiliki aktivitas antioksidan dan tabir surya. Penelitian aktivitas tabir surya pada minyak wijen memberi hasil nilai $S P F$ sebesar 1,77 . Tujuan penelitian ini adalah untuk mendapatkan kombinasi minyak wijen dan minyak biji bunga matahari yang memiliki aktivitas antioksidan dan nilai $S P F$ yang optimal. Metode yang digunakan untuk mengukur aktivitas antioksidan dengan metode peredaman radikal bebas, nilai $S P F$ diperoleh dengan menghitung harga AUC kurva hubungan antara panjang gelombang dengan serapan yang dihasilkan. Hasil penelitian menunjukkan minyak wijen memiliki aktivitas antioksidan ( $\mathrm{IC}_{50}$ ) sebesar $267 \mu \mathrm{g} / \mathrm{mL}$ dan nilai SPF sebesar 1,46 pada konsentrasi $125 \mu \mathrm{g} / \mathrm{mL}$, minyak biji bunga matahari memiliki aktivitas antioksidan (IC50) sebesar 88,37 $\mu \mathrm{g} / \mathrm{mL}$ dan nilai SPF 1,14 pada konsentrasi $125 \mu \mathrm{g} / \mathrm{mL}$, kombinasi kedua minyak memiliki aktivitas antioksidan sebesar ( IC $_{50}$ ) sebesar 118,04 $\mu \mathrm{g} / \mathrm{mL}$ dan nilai SPF 1,78 pada konsentrasi $125 \mu \mathrm{g} / \mathrm{mL}$.
\end{abstract}

Kata kunci: Minyak Wijen (Sesamum indicum L.); minyak biji bunga matahari (Helianthus annuus L.); antioksidan; nilai SPF.

\begin{abstract}
Sesame oil and sunflower seed oil containing Vitamin E and $\beta$-Carotene is reported to have antioxidant activity and sunscreen. Research activity of antioxidants and sunscreen on sesame oil gives the results of SPF value of 1.77. The purpose of this study was to obtain a combination of sesame oil and sunflower seed oil which has antioxidant activity and optimum SPF value. The method used to measure the antioxidant activity by reduction of free radicals, the SPF value is obtained by calculating the AUC curve of the relationship between the wavelength of the absorption generated. The results showed sesame oil has antioxidant activity (IC50) of 267,14 $\mu \mathrm{g} / \mathrm{mL}$ and SPF value of 1.46 in concentration $125 \mu \mathrm{g} / \mathrm{mL}$, sunflower seed oil has antioxidant activity (IC50) of $88,37 \mu \mathrm{g} / \mathrm{mL}$ and SPF value of 1.14 in concentration $125 \mu \mathrm{g} / \mathrm{mL}$, the second combination of oil has antioxidant activity (IC50) amounted to $118.04 \mu \mathrm{g} / \mathrm{mL}$ and $2.54 \mathrm{SPF}$ value in concentration $125 \mu \mathrm{g} / \mathrm{mL}$.
\end{abstract}

Keywords: Sesame Oil (Sesamum indicum L.); sunflower seed oil (Helianthus annuus L.); antioxidants; SPF value

\section{PENDAHULUAN}

Kulit yang terpapar sinar ultraviolet secara terus-menerus menyebabkan elektron atom akan meloncat dari orbitnya, dan terciptalah radikal bebas. Efek oksidatif radikal bebas dapat menyebabkan peradangan dan penuaan dini. Lipid yang seharusnya menjaga kulit agar tetap segar berubah menjadi lipid peroksida karena reaksi radikal bebas sehingga mempercepat proses penuaan. Radiasi sinar ultraviolet (UV) dapat menyebabkan efek merusak dan berbahaya pada kulit. UV-A (ultraviolet A) dan UV-B (ultraviolet B) menyebabkan melanoma kulit, membakar, foto aging, pigmentasi kulit dan berbagai efek lain yang menyakitkan. (Kulkarni et al., 2014)

Manusia melindungi kesehatan tubuh dari berbagai ancaman di lingkungan sekitar sinar matahari, adalah dengan antioksidan dan pemakaian tabir surya. Bahan aktif tabir surya 
digunakan karena dapat menghindarkan seseorang dari kanker kulit. Disamping itu diharapkan dapat meningkatkan kecantikan terutama bagi wanita yang menginginkan kondisi kulit yang sehat.(Ngadiwiyana, Ismiyarto, 2004)

Kulit membutuhkan antioksidan dan tabir surya saat terpapar sinar matahari, terutama untuk wilayah Indonesia yang merupakan negara tropik yang kaya akan limpahan sinar matahari. Karena itu, tak heran para ahli kecantikan menyarankan menggunakan tabir surya setiap hari. Antioksidan dan tabir surya dapat menahan efek yang menyakitkan dari sengatan sinar matahari dan kanker kulit.(Kulkarni et al., 2014)

Menurut studi TGA (Therapeutic Goods Administration) menunjukkan bukti bahwa seng oksida dan titanium oksida dapat menginduksi pembentukan radikal bebas dengan adanya cahaya dan dapat merusak selsel normal (photomutagenecity dengan zinc oxide). Tabir surya yang berasal dari herbal memiliki nilai ekonomis tanpa menyebabkan efek samping berupa komedogenik.(Kulkarni et al., 2014) Penggunaan bahan herbal pada umumnya atau dengan perkecualian tertentu tidak merangsang timbulnya reaksi alergi, tidak menunjukkan efek samping negatif. Kandungan zat aktif yang terdapat dalam tanaman efektif, stabil, murni, efektivitas biaya, mudah tersedia dan ditemukan dalam berbagai macam tanaman.(Kulkarni et al., 2014)

Indonesia yang memiliki kekayaan alam baik flora maupun fauna mengandung begitu banyak tanaman yang berkhasiat sebagai kosmetika khususnya untuk tabir surya. Berdasarkan penelitian sebelumnya diketahui minyak bunga biji matahari (Heliantus annuus L.) memiliki kandungan zat aktif, omega 9, omega 6, vitamin E, lecitin, tocopherol, dan karotenoids.(Kulkarni et al., 2014)(Donglikar and Deore, 2016)(Mishra, Mishra and Chattopadhyay, 2011) Senyawa vitamin E dan tocopherol tersebut diketahui memiliki aktivitas sebagai antioksidan dan tabir surya.(Mishra, Mishra and Chattopadhyay, 2011)(Deore et al., 2012) Demikian juga dengan zat aktif yang terdapat di minyak wijen (Sesamum indicum L.) mengandung asam lemak esensial, vitamin E, sesamin dan sesamol.(Diamita, 2013) Kandungan zat aktif yang dimiliki minyak biji bunga matahari inilah yang memiliki aktivitas sebagai antioksidan dan tabir surya. Kombinasi dari minyak biji bunga matahari dengan minyak wijen sebagai antioksidan dan tabir surya belum pernah diteliti, diharapkan kombinasi keduanya memberikan kerja sinergi dari keduanya.

Berdasarkan hal tersebut maka perlu dilakukan penelitian terhadap kombinasi minyak tanaman wijen (Sesamum indicum L.) dan minyak biji bunga matahari (Heliantus annuus L.) sebagai antioksidan dan menilai Sun Protection Factors (SPF).

\section{METODE PENELITIAN}

Penelitian ini merupakan penelitian eksperimen untuk mengetahui kombinasi minyak biji wijen dengan minyak biji bunga matahari yang dapat mengalami peningkatan nilai antioksidan dan SPF paling optimal.

\section{Alat dan bahan}

Alat yang digunakan yaitu inkubator (Memmert), beaker glass (Pyrex), batang pengaduk, homogenizer, $\mathrm{pH}$ meter (SCHOTT CG 842), viskometer Brookfield, light scattering, oven, lemari pendingin (Samsung), timbangan analitik tipe 210 - LC, spektrofotometer (Optizen).

Bahan-bahan yang digunakan dalam penelitian ini minyak wijen (Sesamum indicum L. seed), minyak biji bunga Matahari (Helianthus annuus L.), reagen DPPH $(1,1$ difenil 2 pikrilhidrazil), Vitamin C, isopropyl alcohol (brataco) ; n-hexan (PT Merck).

\section{Prosedur kerja}

\section{Ekstraksi Minyak Biji Bunga Matahari}

Biji bunga mataharari dikeringkan dan dihaluskan kemudian diayak dengan ayakan ukuran 80 mesh, ditimbang biji bunga matahari sebanyak $10 \mathrm{~kg}$, dimaserasi dengan 20 liter nheksan selama 24 jam. Alat destilasi-vakum yang telah dirangkai dengan kondensor dan labu didih, disiapkan dan dijalankan hingga diperoleh minyak. Saat proses destilasi suhu diluar labu didih $45^{\circ} \mathrm{C}$ dan didalam labu didih $39^{\circ} \mathrm{C}$ dengan tekanan 400 mbar. Destilasi dilakukan selama \pm 2 jam. Biji bunga matahari yang digunakan sebanyak $10 \mathrm{~kg}$ maka akan memperoleh minyak sebanyak 1 liter.

\section{Ekstraksi Minyak Biji Wijen}

Biji wijen dikeringkan dan dihaluskan dengan ditumbuk kemudian diayak dengan ayakan ukuran 80 mesh, ditimbang biji bunga matahari sebanyak $5 \mathrm{~kg}$, dimaserasi dengan 20 
Tabel I. Hasil uji aktivitas antioksidan

\begin{tabular}{lc}
\hline Bahan & IC $\mathbf{5 0}(\boldsymbol{\mu g} / \mathbf{m L})$ \\
\hline Vitamin C & 27,726 \\
Minyak Wijen & 280,473 \\
Minyak Biji Bunga Matahari & 88,372 \\
Kombinasi Minyak Wijen dengan Minyak Biji Bunga Matahari rasio 2:1 & 312,045 \\
\hline
\end{tabular}

liter n-heksan selama 24 jam. Disiapkan alat destilasi-vakum yang telah dirangkai dengan kondensor dan labu didih lalu dijalankan alat tersebut hingga diperoleh minyak. Saat proses destilasi suhu diluar labu didih 450C dan didalam labu didih 390C dengan tekanan 400 mbar. Destilasi berjalan selama +2 jam. Biji wijen yang digunakan sebanyak $5 \mathrm{~kg}$ maka akan memperoleh minyak sebanyak 2 liter.

Karakterisasi Minyak

Karakaterisasi minyak meliputi: Analisa komposisi asam lemak menggunakan alat GCFID ; analisa bilangan iod, penyabunan, peroksida, dan asam dengan menggunakan metode titrimetri ; analisa karotenoid menggunakan metode TLC scanner; analisa vitamin E menggunakan metode HPLC

Uji Aktivitas Antioksidan (Ika Agustina, 2015) Pengujian aktivitas antioksidan menggunakan metode peredaman radikal bebas (DPPH). Aktivitas antioksidan dinyatakan dengan nilai IC $_{50}$ dengan satuan $\mu \mathrm{g} / \mathrm{mL}$. Langkah awal adalah dengan membuat larutan DPPH 100 $\mu \mathrm{g} / \mathrm{mL}$, kemudian membuat deret konsentrasi untuk setiap sampel dengan konsentrasi 20, 40, 70, 90, dan $100 \mu \mathrm{g} / \mathrm{mL}$. Ambil $4 \mathrm{~mL}$ larutan untuk setiap konsentrasi kemudian ditambahkan $1 \mathrm{~mL}$ larutan DPPH $100 \mu \mathrm{g} / \mathrm{mL}$, baca serapan pada panjang gelombang $515 \mathrm{~nm}$. Persentase (\%) inhibisi oksidase dapat dihitung dengan cara:

$\%$ Inhibisi $=$

(nilai serapan blanko - nilai serapan sampel)

$\times 100 \%$

Uji Nilai SPF(Rosita, Purwanti and Agustin, 2010)

100 mg sampe ditimbang seksamal, dilarutkan dalam isopropyl alkohol hingga 100,0 mL (1000 ppm), kemudian dibuat konsentrasi 125 ppm dan 500 ppm, diukur serapannya dengan spektrofotometer pada rentang panjang gelombang 290 sampai $370 \mathrm{~nm}$ dengan interval $5 \mathrm{~nm}$. Dihitung area di bawah kurva (AUC) dari nilai serapan pada panjang gelombang 290-370 $\mathrm{nm}$ dengan interval 5 nm. Dihitung nilai log SPF dengan cara membagi jumlah seluruh area dibawah kurva dengan selisih panjang gelombang terbesar dan terkecil kemudian dikalikan 2 . Selanjutnya mengubah nilai log SPF menjadi nilai SPF.

Nilai AUC dihitung menggunakan rumus:

$$
\mathrm{AUC}=(\mathrm{Aa}+\mathrm{Ab}) / 2 \times(\mathrm{dPa}-\mathrm{b})
$$

$\mathrm{Aa}=$ Absorbansi pada panjang gelombang a $\mathrm{nm}$; $\mathrm{Ab}=$ Absorbansi pada panjang gelombang $\mathrm{b} \mathrm{nm}$; $\mathrm{dPa}-\mathrm{b}=$ Selisih panjang gelombang $\mathrm{a}$ dan $\mathrm{b}$.

\section{HASIL PENELITIAN DAN PEMBAHASAN}

$\mathrm{IC}_{50}$ merupakan nilai yang menunjukan kemampuan penghambatan proses oksidasi sebesar 50\% suatu konsentrasi sampel (ppm). Nilai $\mathrm{IC}_{50}$ yang semakin kecil maka menunjukkan semakin tingginya aktivitas antioksidan. Suatu zat atau senyawa dikatakan memiliki nilai aktivitas antioksidan sangat kuat jika IC 50 kurang dari 50 ppm, antioksidan kuat jika nilai $\mathrm{IC}_{50}$ antara 50-100ppm, antioksidan sedang jika IC 50 bernilai 100-250 ppm, antioksidan lemah jika IC $_{50}$ bernilai 250-500 ppm, dan antioksidan tidak aktif jika $\mathrm{IC}_{50}$ bernilai > 500 ppm. (Jun M, Fu HY, Hong J, Wang $\mathrm{X}$,Yang CS, 2006).

Berdasarkan tabel I diketahui hasil pengukuran aktivitas antioksidan minyak biji wijen, biji matahari dan kombinasi minyak antara lain: Minyak biji wijen diperoleh nilai IC $_{50}$ sebesar 280,473 $\mu \mathrm{g} / \mathrm{mL}$, sehingga hasil pengujian yang diperoleh menyatakan bahwa minyak wijen memiliki aktivitas antioksida lemah, apabila dibandingkan dengan hasil pengujian vitamin $\mathrm{C}$ yang memiliki aktivitas antioksidannya lebih tinggi dibandingkan minyak wijen yaitu 27,726 $\mu \mathrm{g} / \mathrm{mL}$.

Berdasarkan hasil pengukuran aktivitas antioksidan minyak biji bunga matahari diperoleh nilai $\mathrm{IC}_{50}$ sebesar 88,372 $\mu \mathrm{g} / \mathrm{mL}$, sehingga dapat dikelompokkan ke dalam 
Tabel II. Hasil uji nilai SPF pada Konsentrasi 125 g/mL

\begin{tabular}{lc}
\hline Bahan & SPF \\
\hline Minyak Wijen & 1,522 \\
Minyak Biji Bunga Matahari & 1,25 \\
Kombinasi Minyak Wijen dengan Minyak Biji Bunga Matahari Rasio 2:1 & 4,904 \\
\hline
\end{tabular}

antioksidan yang memiliki aktivitas kuat. Adanya aktivitas antioksidan dari minyak biji bunga matahari yang memiliki kandungan vitamin E yang cukup tinggi yaitu sebesar 58,7 dan $\beta$ - karoten sebesar 1,87, dimana kedua kandungan senyawa tersebut bermanfaat sebagai antioksidan.

Berdasarkan hasil pengukuran aktivitas antioksidan yang paling optimal adalah kombinasi minyak wijen dengan minyak biji bunga matahari rasio $2: 1$ diperoleh nilai $\mathrm{IC}_{50}$ sebesar 312,045 $\mu \mathrm{g} / \mathrm{mL}$, sehingga dapat dikelompokkan ke dalam antioksidan yang memiliki aktivitas lemah. Jika dibandingkan dengan Vitamin C, aktivitas antioksidan lebih tinggi dibandingkan kombinasi kedua minyak tersebut.

Hasil pengujian nilai SPF ditampilkan pada tabel II, dari tabel diatas menunjukkan bahwa minyak wijen memiliki nilai SPF 1,45. Minyak biji bunga matahari memiliki nilai SPF 1,14 sedangkan kombinasi kedua minyak memiliki nilai SPF 1,78. Nilai SPF yang diperoleh dari hasil pengukuran menunjukkan minyak wijen, minyak biji bunga matahari, dan kombinasi kedua minyak adalah rendah. Peningkatan nilai SPF pada kombinasi minyak wijen dan minyak biji bunga matahari terjadi karena kandungan zat aktif kedua minyak tersebut bersinergis.

\section{KESIMPULAN}

Kombinasi minyak biji wijen dengan biji bunga matahari yang menghasilkan aktivitas antioksidan dan nilai SPF yang optimal adalah dengan rasio 2:1 (minyak biji wijen : minyak biji bunga matahari) dengan nilai IC $_{50}$ sebesar $312,045 \mu \mathrm{g} / \mathrm{mL}$, memberikan efek antagonis. Nilai SPF sebesar 1,78 pada konsentrasi 125 $\mu \mathrm{g} / \mathrm{mL}$, memberikan efek sinergis.

\section{DAFTAR PUSTAKA}

Deore, S. L. et al., (2012) 'Photoprotective Antioxidant Phytochemicals', International Journal of Phytopharmacy, 2(3), pp. 3-8.
Diamita, A. A. (2013) 'Pengaruh Pemberian Minyak Wijen (Sesamum indicum Linn.) Dengan Cold Press Bertingkat Terhadap Kerusakan Histologis Lambung Mencit Yang Dinduksi Aspirin', 84, pp. 487-492. Available at: http://ir.obihiro.ac.jp/dspace/handle/1 0322/3933.

Donglikar, M. M. and Deore, S. L. (2016) 'Development and Evaluation of Herbal Sunscreen', Pharmacognosy Journal, 9(1), pp. 83-97.

Ika Agustina (2015) Pengembangan Minyak Buah Merah (Pandanus Conoideus) Sebagai Antioksidan Dan Pelembab Dalam Sediaan Losion Mikroemulsi Untuk Perawatan Bibir.

Jun M, Fu HY, Hong J, Wang X,Yang CS, H. C. (2006) 'No Title', Comparison of antioxidant activities of isoflavones from kudzu root (Pueraria lobate ohwi), pp. 2117-2122. Available at: https://pubag.nal.usda.gov/catalog/387 515.

Kulkarni, S. S. et al., (2014) 'Herbal Plants in Photo Protection and Sun Screening Action: an Overview', Indo American Journal of Pharmaceutical Research American Journal of Pharm Research, 4(2), pp. 1104-1113. Available at: http://www.iajpr.com/index.php/en/.

Mishra, A. K., Mishra, A. and Chattopadhyay, P. (2011) 'Herbal cosmeceuticals for photoprotection from ultraviolet B radiation: A review', Tropical Journal of Pharmaceutical Research, 10(3), pp. 351360.

Ngadiwiyana, Ismiyarto, K. A. (2004) 'Pemanjangan Sistem Terkonjugasi Sinamaldehid', JKSA, VII(1), pp. 24-29.

Rosita, N., Purwanti, T. and Agustin (2010) 'Stabilitas Fisik dan Efektivitas Sediaan Tabir Surya Kombinasi Oksibenson dan Oktil Metoksisinamat dengan Penambahan Asam Glikolat', VII(2), pp. 16-26. 